\title{
(2) OPEN ACCESS \\ Self-harm injury hospitalisations: an analysis of case selection criteria
}

\author{
Pamela Imm 다, ${ }^{1}$ Brittany Grogan, ${ }^{2}$ Ousmane Diallo ${ }^{3}$
}

- Additional material is published online only. To view please visit the journal online (http://dx.doi.org/10.1136/ injuryprev-2019-043514).

'University of Wisconsin Population Health Institute, University of WisconsinMadison, Madison, Wisconsin, USA

${ }^{2}$ Public Health Madison \& Dane County, City of Madison Wisconsin, Madison, Wisconsin, USA

${ }^{3}$ Wisconsin Department of Health Services, Wisconsin Division of Public Health, Madison, Wisconsin, USA

\section{Correspondence to}

Ms Pamela Imm, University of Wisconsin-Madison, University of Wisconsin Population Health Institute, Madison, WI 53703, USA; Pamela.Imm@dhs. wisconsin.gov

Received 2 January 2020 Revised 13 May 2020 Accepted 21 May 2020

\section{ABSTRACT \\ Background This study explores the impact of using different criteria to identify nonfatal hospitalisations with self-harm injuries using 2017-2018 Wisconsin discharge data.}

Methods Using International Classification of Diseases, 10th Revision, Clinical Modification codes, we classified records by three mutually exclusive selection criteria: subset A--principal diagnosis of injury, and any code for self-harm, initial encounter only; subset B--noninjury principal diagnosis, and any code for self-harm, initial encounter only; subset C--any principal diagnosis, and any code for self-harm, subsequent and sequelae encounters only. These categories were used to conduct two separate logistic regression models. Model 1 analysed the impact of surveillance limited to a principal diagnosis of injury, initial self-harm encounter (subset B compared with A). Model 2 analysed the impact if limited to initial encounters for self-harm, regardless of principal diagnosis (subset $C$ compared with $(A+B)$ ). Both patientlevel and visit-level analyses were conducted.

Results For both patient-level models, subsets that included additional records based on an expansion of selection criteria were significantly more likely to include children (model 1: OR 2.8, model 2: OR 2.9; compared with those $25-54$ years), those with mental health disorders (model 1: OR 6.5, model 2: OR 4.3) and rural residents (model 1: OR 1.2, model 2: OR 1.4). Drug-related disorder and means of self-harm were significantly different among subsets for both models. Visit-level analyses revealed similar results.

Discussion Expanding case selection criteria would better capture the scale of hospitalisation for nonfatal self-harm. Using restrictive selection criteria may result in biased understanding of the affected populations, potentially impacting the development of policy and prevention programmes.

\section{BACKGROUND}

Self-inflicted violence, with or without suicidal intent, is a public health emergency. For over a decade, self-harm by poisoning has ranked among the top five leading causes of injury emergency department (ED) visits resulting in hospitalisation in the USA (all ages) and second among those aged 15-24. ${ }^{1}$ Self-harm by other means (cutting and other specified means) has ranked among the top 20 leading causes of death. ${ }^{1}$ Furthermore, selfharming behaviours have been increasing and are especially prevalent among youth. ${ }^{1-3}$ Studies have found that those who self-harm are more likely to repeat the behaviour and are at increased risk of suicide. ${ }^{4-12}$ The urgency of addressing this problem is evident as suicide is consistently a leading cause of death ${ }^{13}$ and the suicide rate in the USA has been increasing for nearly two decades (up 34\% from 1999 to 2017). ${ }^{1}$ Wisconsin has experienced an even greater increase $(40 \%)$ over this period. ${ }^{1}$

Surveillance of self-inflicted injury is essential to understanding burden and changes over time. However, data on nonfatal self-harm are not systematically collected and reported at the national, state or local level. ${ }^{14}$ Surveillance for selfharm and injuries of all types is often conducted by monitoring ED visits and inpatient hospitalisations. Since the 1970s, administrative claims data from these settings have been coded using the International Classification of Diseases, Ninth Revision, Clinical Modification (ICD-9-CM). In October 2015, the US Department of Health and Human Services mandated that all entities covered by the Health Insurance Portability and Accountability Act use the Tenth Revision (ICD-10-CM) when reporting medical care information. This transition to ICD-10-CM helped enhance data quality, support comparable morbidity and mortality data, and allow international comparisons. ${ }^{15}$ The transition resulted in significant changes. Thousands more injury diagnosis and external cause codes were added allowing for greater specificity including: exact cause of injury, specific type of anatomic/ physiologic injury and encounter type (ie, initial, subsequent or sequelae). ${ }^{15} 16$

In 2019, the US Centers for Disease Control and Prevention (CDC) published recommendations for an injury hospitalisation case definition based on ICD-10-CM codes. ${ }^{17}$ These recommendations focused on the creation of an injury subset that included records indicating an initial encounter for active treatment of an injury as the principal diagnosis (ie, the condition chiefly responsible for admission). ${ }^{1718}$ Once the injury subset has been created, all diagnoses and external cause of morbidity codes noting an initial encounter are reviewed and the case is categorised by intent and mechanism of injury. Identification of cases involving intentional self-harm requires review of both diagnosis and external cause codes as some causes are reflected in unique diagnoses codes (poisoning, asphyxiation and suicide attempt) while others are reflected in unique external cause codes (all other means of intentional self-harm, such as cutting or firearms).

Though the CDC-recommended injury hospitalisation case definition restricts case selection to a subset based on principal diagnosis of injury, an earlier CDC publication indicated that, for self-harm, other considerations may be appropriate. ${ }^{19}$ One consideration involves expansion of 


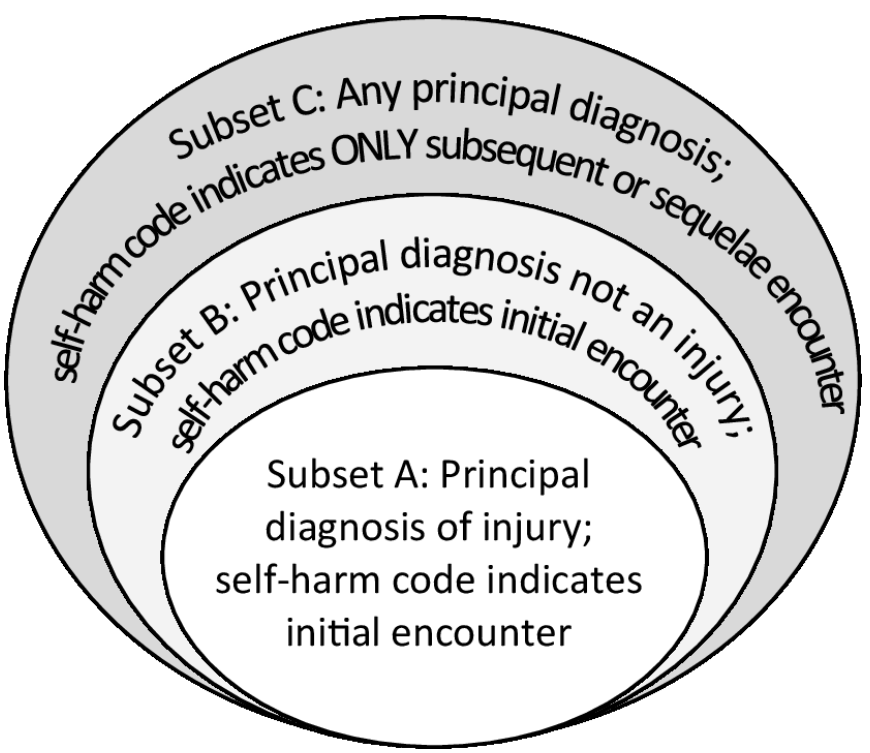

Figure 1 Universe of nonfatal hospitalisations with any selfharm International Classification of Diseases, $10^{\text {th }}$ Revision, Clinical Modification (ICD-10-CM) code.

the definition to include visits with any mention of self-harm (regardless of principal diagnosis). Studies have found strong associations between self-harm injuries and mental health disorders. ${ }^{6-1020-23}$ These disorders may be prioritised in the principal diagnosis field and excluded from an injury subset that requires an injury principal diagnosis. Another consideration involves an exploration of encounter types. ICD-10-CM employs different codes to identify initial encounters (active treatment for a condition), subsequent encounters (routine care during recovery phase) and encounters for sequelae of injury (indicating complications or conditions that arise from a previous injury). ICD-10-CM coding allows for restriction of case selection to initial encounters only; however, this may not be useful or relevant for self-harm, as these injuries can differ from those of other intents. Self-harm injuries are more likely to be repeated, have more return visits to the ED or hospital, and are more likely to result in suicide compared with other injuries. ${ }^{4-12} 2024$ This repeated nature may require consideration of all encounter types, especially if self-harm is viewed as an ongoing health condition requiring active attention.

The purpose of this study is to explore the impact of different case selection criteria of varying inclusivity to develop a standardised surveillance case definition for hospitalisations with ICD-10-CM codes noting self-harm.

\section{METHODS}

\section{Data sources and study population}

This study analysed nonfatal hospitalisation data provided by the Wisconsin Hospital Association (WHA) based on discharge dates from January 2017 to December 2018. Per Wisconsin State Statutes, hospitals are required to submit discharge data to the Wisconsin Department of Health Services for all hospital discharges. ${ }^{25}$

Our study population was restricted to Wisconsin residents discharged from Wisconsin hospitals with an ICD-10-CM code noting self-harm; 11118 hospitalisations representing 9093 patients. The analytical file had nine diagnoses fields (including one principal diagnosis field) and two external cause of morbidity fields. Since 2013, WHA has included a unique patient identifier in the dataset which made it possible to link multiple hospitalisations to the same patient and perform patient-level analyses.
All analyses were conducted at the patient-level, based on data from the first hospitalisation noting self-harm during the study period, and at the visit-level (including repeat visits by same patient; see online supplementary tables 1 and 2).

\section{Self-harm case selection criteria and subset categorisation}

Hospitalisation records were categorised into three mutually exclusive subsets which, when totalled, equals the entire universe of stays with a self-harm ICD-10-CM code (figure 1). Subset A was restricted to stays with a principal diagnosis of injury. The first step for classification was to identify an ICD-10-CM code indicating an initial encounter for an injury (any type) of any intent (unintentional, intentional or unspecified) (table 1) in the principal diagnosis field. The second step for subset A was identification of records with a self-harm injury code, initial encounter only, in any of the diagnosis or external cause fields. Additional information provided in the seventh character of the ICD-10-CM code details the type of encounter. For subset A, only records with codes indicating an initial encounter of selfharm were included (codes missing a seventh character were considered to be an initial encounter).

Subset B included cases with a non-injury principal diagnosis and initial encounter for self-harm in any of the other diagnosis or external cause fields. Though injury was not the principal diagnosis, an injury diagnosis code did appear in one of the other eight diagnosis fields in $93 \%$ of subset B cases. Subset C was composed of cases with any type of principal diagnosis and a self-harm code, in any field, noting only a subsequent or sequelae encounter. Ninety-nine per cent (99\%) of subset C cases had an injury diagnosis in one of the eight secondary diagnosis fields.

\section{Measures}

Subset categorisation served as the dependent variable (outcome). Independent variables (predictors) included patient demographics: age, gender, race and urban or rural residency. Age at admission was categorised into four groups (children: $<18$, young adults: 18-24, working age adults: 25-54, and older adults: 55 and older). Ages ranged from 4 to 96 years old. Race (inclusive of Hispanic and non-Hispanic ethnicity) was classified as white, black or other. County of residence was categorised as rural or urban using the Wisconsin Office of Rural Health determination. ${ }^{26}$

Other self-harm determinants included means and comorbidities. These were created as dichotomous variables and all diagnoses and external cause fields were reviewed (any encounter type). Means of self-harm included cutting, drug poisoning, non-drug poisoning and all other means (see table 1 for list of ICD-10-CM codes). Comorbidities included mental, behavioural and neurodevelopmental disorders (hereafter referred to as mental health disorders; inclusive of conditions defined in Chapter 5 of the ICD-10-CM codebook, ${ }^{27}$ excluding substance related disorders which were analysed separately) and drug and alcohol-related disorders. The Charlson Comorbidities Index was employed to create a chronic disease index ${ }^{28}$ noting the presence of zero, one, or two or more chronic diseases.

To assess the effect of repeated self-harm hospitalisation (patient-level analysis), the number of hospitalisations (20172018) was calculated for each patient and categorised as one, two or three or more visits.

\section{Analytic plan}

Descriptive analysis

All data were analysed using SAS V.9.4. Univariate analyses were conducted to estimate differences in the distribution of the covariates between dependent categories. Cochran-Mantel-Haenszel 
Table 1 ICD-10-CM* injury and self-harm codes and descriptions

\begin{tabular}{|c|c|}
\hline ICD-10-CM codes & Description \\
\hline \multicolumn{2}{|c|}{ Injury diagnosis codest: Subset A classification requires one of these codes listed as principal diagnosis } \\
\hline S00-S99 & Anatomic injuries \\
\hline T07-Т34 & Foreign bodies, burns, corrosions, frostbite \\
\hline $\begin{array}{l}\text { T36-T50 with a 6th character of 1, 2, 3, or } 4 \text {. Note: include T36.9, T37.9, T39.9, } \\
\text { T41.4, T42.7, T43.9, T45.9, T47.9, and T49.9 with a 5th character of 1, 2, 3, or } 4 .\end{array}$ & $\begin{array}{l}\text { Poisoning by drugs, medicaments and biological substances (excludes adverse effects and } \\
\text { underdosing) }\end{array}$ \\
\hline T51-T65 & Toxic effects of nonmedicinal substances \\
\hline T66-T76 & Other and unspecified effects of external causes \\
\hline T79 & Certain early complications of trauma, not elsewhere classified \\
\hline 09A.2-09A.5 & Traumatic injuries and abuse complicating pregnancy, childbirth, and the puerperium \\
\hline M97 & Periprosthetic fracture around internal prosthetic joint \\
\hline \multicolumn{2}{|c|}{ Self-harm codesł: Diagnosis and external cause codes detailing means of self-harm } \\
\hline $\begin{array}{l}\text { X71-X77, X79-X83 (external cause codes); T71, T54.1 T54.2, T54.3, T63.0-T63.8, } \\
\text { T65.82 (6th character=2); T54.9,T63.9 (5th character=2) (diagnosis codes) }\end{array}$ & $\begin{array}{l}\text { Other means: drowning/submersion, firearm, explosive material, fire/flame, hot vapours/ } \\
\text { objects, blunt object, jumping from a high place, jumping or lying in front of a moving object } \\
\text { crashing of motor vehicle, asphyxiation, suffocation, hanging, other specified means }\end{array}$ \\
\hline X78 (external cause code) & Cutting: sharp object \\
\hline $\begin{array}{l}\text { T36-T50 with 6th character=2 (note: include T36.9, T37.9, T39.9, T41.4, T42.7, } \\
\text { T43.9, T45.9, T47.9, and T49.9 with 5th character=2) (diagnosis codes) }\end{array}$ & Drug poisoning: drugs, medications and biological substances \\
\hline
\end{tabular}

T43.9. T45. 9 T47.9, and T49.9 with 5th character=2) (diagnosis codes)

T51-T53, T55-T62, T64, T54.0, T65.0, T65.1, T65.2, T65.3, T65.4, T65.5, T65.6, T65.81， Non-drug poisoning: toxic effects of non-medicinal substances

T65.83, T65.89 with 6th character=2 (note: include T51.9, T52.9, T53.9, T56.9, T57.9,

T58.0, T58.1, T58.9, T59.9, T60.9, T61.0, T61.1, T61.9, T62.9, T64.0, T64.8, T65.9 with

a 5 th character $=2$ ) (diagnosis codes)

T14.91 (diagnosis code)

Unspecified means: suicide attempt

*International Classification of Diseases, 10th Revision, Clinical Modification.

77th character of $A, B, C$ or missing required for subset $A$ classification (reflects initial encounter, active treatment).

$\$ 7$ th character of $A$ or missing=initial encounter, active treatment; $D=$ follow-up or subsequent encounter; $S=$ sequelae encounter.

general association tests were performed for each independent variable of interest against the dependent variable. Before age was recoded as a categorical variable for the regression analyses, a t-test was conducted to assess the difference between subset means.

\section{Logistic regression}

Two separate logistic regression models were run based on subset classification. Model 1 analysed the impact of surveillance limited to a principal diagnosis of injury, initial self-harm encounter (comparison of subset B to subset A). Model 2 analysed the impact of surveillance limited to initial encounters for self-harm, regardless of principal diagnosis (subset $C$ compared with subset $(A+B)$ ). This iterative analysis allowed us to determine if the cases added by each expansion of the selection criteria were significantly different by our independent variables.

Saturated logistic regression models were employed for both models and included all independent variables found to be statistically significant $(\mathrm{p} \leq 0.05)$ in the univariate analysis. Any variables that did not remain significant in the model were removed. Model testing and fit were conducted using Akaike Information Criteria (AIC $=-2 \times \operatorname{LogL}+2 \times$ number of parameters); the final model proved a better fit, with a lower AIC score, than the saturated and intercept models. Patient-level results are presented separately for each model.

\section{RESULTS}

\section{Model 1}

Descriptive analysis

Table 2 details the patient-level demographic composition for model 1 . The age distribution revealed a younger population among those without a principal diagnosis of injury: $27 \%$ of cases in subset B were children ( $<18$ years of age) compared with $12 \%$ in subset $A$. The mean age was significantly younger in subset B as well $(\mathrm{p}<0.0001)$. Patient geography was notably different by subset: the percentage of rural residents in subset $B$ was significantly higher compared with subset A ( $26 \%$ vs $23 \%$; $\mathrm{p}=0.0027$ ).

There were significant differences between subsets by means of self-harm and comorbidities. Self-harm by cutting was much more frequent in subset B (33\% compared with 6\% among subset A), while self-harm by poisoning (both drug and nondrug) was significantly more common among subset A. For stays with self-harm poisoning as principal diagnosis (3984 patients; $89 \%$ of subset A), these would result in automatic inclusion in subset A which largely explains its greater frequency as means of self-harm in this subset.

Comorbidities of mental health disorders, suicidal ideation, personal history of self-harm and drug-related disorders were more common in subset B. Ninety-six per cent of cases in subset $B$ had a mental health disorder (in any diagnosis field) (table 2). Eighty-seven per cent $(87 \%)$ of this subset had a principal diagnosis of mental health disorder (not inclusive of substance related disorders) resulting in automatic exclusion from subset $\mathrm{A}$ (data not shown). An additional $7 \%$ of subset B had a principal diagnosis of alcohol or drug-related disorder.

\section{Logistic regression analysis}

Patient-level logistic regression analysis revealed that subset B was more likely to include cases who were younger and residents of rural counties. Compared with adults aged 25-54 (referent group), subset B was 2.8 times more likely to include children $(<18$ years $)$ and $50 \%$ more likely to include young adults (18-24) than subset A (table 2). Subset B was also $20 \%$ more likely to include rural county residents compared with subset A.

Subset B was 6.5 times more likely to include cases with mental health disorders as subset A. Drug-related disorders were also significantly different between groups: subset B was $60 \%$ more likely to include cases with these disorders, compared with subset A. Subset B was 70\% more likely to include cases noting suicidal ideation compared with subset $\mathrm{A}$. 
Table 2 Model 1 patient-level demographics $\ddagger$ and ORs by type of principal diagnosis (injury or non-injury) and initial encounter for selfharm

\begin{tabular}{|c|c|c|c|}
\hline & $\begin{array}{l}\text { Principal diagnosis } \\
\text { of injury; self-harm } \\
\text { code indicates } \\
\text { initial encounter }\end{array}$ & $\begin{array}{l}\text { Principal diagnosis } \\
\text { not an injury; } \\
\text { self-harm code } \\
\text { indicates initial } \\
\text { encounter }\end{array}$ & $\begin{array}{l}\text { OR Estimate } \\
(95 \% \mathrm{Cl})\end{array}$ \\
\hline & Subset A & Subset B & Subset B* \\
\hline Category & N (\%) & N (\%) & \\
\hline Total & $4457(100)$ & $2806(100)$ & \\
\hline \multicolumn{4}{|l|}{ Discharge year } \\
\hline 2017 & $2495(56)$ & $1525(54)$ & \\
\hline 2018 & 1962 (44) & $1281(46)$ & \\
\hline \multicolumn{4}{|l|}{ Age (in years) $\dagger$} \\
\hline $0-17$ & $553(12)$ & 744 (27) & 2.8 (2.4 to 3.3$)$ \\
\hline $18-24$ & 798 (18) & $650(23)$ & 1.5 (1.3 to 1.7$)$ \\
\hline $25-54$ & 2372 (53) & $1151(41)$ & (referent) \\
\hline $55+$ & 734 (17) & $261(9)$ & 0.8 (0.7 to 1.0$)$ \\
\hline Mean & 37 & 30 & \\
\hline Median & 35 & 25 & \\
\hline \multicolumn{4}{|l|}{ Gender } \\
\hline Male & $1758(39)$ & 1059 (38) & \\
\hline Female & $2699(61)$ & 1747 (62) & \\
\hline \multicolumn{4}{|l|}{ Race $†$} \\
\hline White & 3661 (82) & $2328(83)$ & (referent) \\
\hline Black & $451(10)$ & $220(8)$ & 0.7 (0.6 to 0.9$)$ \\
\hline Other/unknown & $345(8)$ & $258(9)$ & 0.9 (0.7 to 1.1) \\
\hline \multicolumn{4}{|l|}{ Geography $\dagger$} \\
\hline $\begin{array}{l}\text { Urban county } \\
\text { residence }\end{array}$ & $3443(77)$ & $2081(74)$ & (referent) \\
\hline $\begin{array}{l}\text { Rural county } \\
\text { residence }\end{array}$ & $1014(23)$ & 725 (26) & 1.2 (1.1 to 1.4$)$ \\
\hline \multicolumn{4}{|l|}{$\begin{array}{l}\text { Means of self- } \\
\text { harm }\end{array}$} \\
\hline Cuttingt & $282(6)$ & $933(33)$ & 2.2 (1.8 to 2.8 ) \\
\hline $\begin{array}{l}\text { Poisoning: } \\
\text { drugst }\end{array}$ & $3940(88)$ & $1228(44)$ & 0.1 (0.1 to 0.2$)$ \\
\hline $\begin{array}{l}\text { Poisoning: non- } \\
\text { drugst }\end{array}$ & $461(10)$ & $139(5)$ & 0.5 (0.4 to 0.7$)$ \\
\hline Other means $†$ & $297(7)$ & $622(22)$ & 1.4 (1.1 to 1.8$)$ \\
\hline \multicolumn{4}{|l|}{ Comorbidities } \\
\hline $\begin{array}{l}\text { Mental, } \\
\text { behavioural and } \\
\text { neurological } \\
\text { disorders (F00- } \\
\text { F09, F20-F99)† }\end{array}$ & 3597 (81) & $2698(96)$ & 6.5 (5.1 to 8.2 ) \\
\hline $\begin{array}{l}\text { Suicidal ideation } \\
\text { (R45.851) } \dagger\end{array}$ & $528(12)$ & $687(24)$ & 1.7 (1.5 to 2.0$)$ \\
\hline $\begin{array}{l}\text { History of self- } \\
\text { harm (Z91.5)† }\end{array}$ & $348(8)$ & 390 (14) & 1.2 (1.0 to 1.4$)$ \\
\hline $\begin{array}{l}\text { Drug related } \\
\text { disorder } \\
\text { (F11-F19)† }\end{array}$ & $1519(34)$ & $1207(43)$ & 1.6 (1.4 to 1.8$)$ \\
\hline $\begin{array}{l}\text { Alcohol related } \\
\text { disorder (F10) }\end{array}$ & $969(22)$ & $658(23)$ & \\
\hline \multicolumn{4}{|l|}{$\begin{array}{l}\text { Chronic } \\
\text { Diseases Indext }\end{array}$} \\
\hline Zero & $3375(76)$ & $2233(80)$ & \\
\hline One & 868 (19) & 505 (18) & \\
\hline
\end{tabular}

Table 2 Continued

\begin{tabular}{|c|c|c|c|}
\hline & $\begin{array}{l}\text { Principal diagnosis } \\
\text { of injury; self-harm } \\
\text { code indicates } \\
\text { initial encounter }\end{array}$ & $\begin{array}{l}\text { Principal diagnosis } \\
\text { not an injury; } \\
\text { self-harm code } \\
\text { indicates initial } \\
\text { encounter }\end{array}$ & $\begin{array}{l}\text { OR Estimate } \\
(95 \% \mathrm{Cl})\end{array}$ \\
\hline & Subset A & Subset B & Subset $B^{*}$ \\
\hline Category & N (\%) & N (\%) & \\
\hline Two or more & $214(5)$ & $68(2)$ & \\
\hline \multicolumn{4}{|l|}{ No of visitst } \\
\hline One & $3568(80)$ & $2472(88)$ & (referent) \\
\hline Two & $693(16)$ & $249(9)$ & 0.4 (0.3 to 0.5$)$ \\
\hline Three or more & $196(4)$ & $85(3)$ & 0.5 (0.3 to 0.7$)$ \\
\hline
\end{tabular}

Some rounding error for age group percentages in order to total $100 \%$. Comorbidities include list of relevant International Classification of Diseases, 10th Revision, Clinical Modification (ICD-10-CM) codes in parentheses (all diagnoses fields reviewed). Chronic Disease Index based on Charlson Comorbidities Index.

${ }^{*}$ Compared to subset $A$.

tCochran-Mantel-Haenszel general association $\mathrm{p} \leq 0.05$.

‡Based on information from first discharge during 2017-2018 period.

Cutting and other means of self-harm had a greater likelihood of identification among subset $\mathrm{B}$, while poisoning (drug and nondrug) was identified more often in subset A (the latter largely explained by prioritisation of self-harm poisoning as principal diagnosis in subset A).

\section{Model 2}

Descriptive analysis

Model 2 revealed even greater differences (compared with model 1) between subsets by age categories: $40 \%$ of cases in subset $\mathrm{C}$ were children compared with $18 \%$ of subset $(\mathrm{A}+\mathrm{B})-\mathrm{a}$ difference of 22\% (table 3). Differences by geography were also greater in model 2: rural residents were more frequently categorised in subset $\mathrm{C}$ compared with subset $(\mathrm{A}+\mathrm{B})(31 \%$ vs $24 \%$, respectively; $\mathrm{p}<0.0001$ ).

Self-harm by cutting was more frequent in subset $\mathrm{C}$ compared with subset $(A+B)$ though this difference was much less than the model 1 comparison ( $16 \%$ vs $27 \%$ difference, respectively). Self-harm poisoning differences between subsets narrowed but remained significant.

Comorbidities followed similar patterns as in model 1 . Compared with subset $(\mathrm{A}+\mathrm{B})$, subset $\mathrm{C}$ included a greater percentage of cases with mental health disorders and those with a history of self-harm.

\section{Logistic regression analysis}

As with model 1, the subset including additional cases identified by expansion of case selection criteria (subset C) was significantly younger and more likely to be rural (table 3 ). Subset C was over four times more likely to identify cases with mental health disorders as its comparison group (subset $(\mathrm{A}+\mathrm{B})$ ) and $50 \%$ more likely to identify those with drug-related disorders. The difference between subsets for history of self-harm was even greater than that noted for model 1: subset $C$ was $40 \%$ more likely to identify these cases (compared with subset $(\mathrm{A}+\mathrm{B})$ ).

Cutting and other means of self-harm were more likely among subset $\mathrm{C}(\mathrm{OR}=2.6$ and 2.7 , respectively). The scale of these differences was greater than that found in model 1 subset comparisons. 
Table 3 Model 2 patient-level demographics $\ddagger$ and ORs by type of encounter (initial encounter code of self-harm versus subsequent or sequelae encounter)

\begin{tabular}{|c|c|c|c|}
\hline \multirow[b]{3}{*}{ Category } & $\begin{array}{l}\text { Any principal } \\
\text { diagnosis; } \\
\text { self-harm code } \\
\text { indicates initial } \\
\text { encounter }\end{array}$ & $\begin{array}{l}\text { Any principal } \\
\text { diagnosis; self-harm } \\
\text { code indicates } \\
\text { ONLY subsequent or } \\
\text { sequelae encounter }\end{array}$ & $\begin{array}{l}\text { OR estimate } \\
(95 \% \mathrm{Cl})\end{array}$ \\
\hline & Subset $(A+B)$ & Subset C & Subset $C^{*}$ \\
\hline & N (\%) & \multicolumn{2}{|l|}{$\mathrm{N}(\%)$} \\
\hline Total & $7263(100)$ & \multicolumn{2}{|l|}{$1830(100)$} \\
\hline \multicolumn{4}{|l|}{ Discharge year } \\
\hline 2017 & $4020(55)$ & \multicolumn{2}{|l|}{$987(54)$} \\
\hline 2018 & $3243(45)$ & \multicolumn{2}{|l|}{$843(46)$} \\
\hline \multicolumn{4}{|l|}{ Age (in years) $\dagger$} \\
\hline$<18$ & $1297(18)$ & $730(40)$ & 2.9 (2.5 to 3.3$)$ \\
\hline $18-24$ & $1448(20)$ & $341(18)$ & 1.1 (1.0 to 1.3$)$ \\
\hline $25-54$ & $3523(48)$ & $636(35)$ & (referent) \\
\hline $55+$ & 995 (14) & $123(7)$ & 0.9 (0.7 to 1.1$)$ \\
\hline Mean & 34 & \multicolumn{2}{|l|}{27} \\
\hline Median & 31 & \multicolumn{2}{|l|}{20} \\
\hline \multicolumn{4}{|l|}{ Gender } \\
\hline Male & $2817(39)$ & \multicolumn{2}{|l|}{$713(39)$} \\
\hline Female & $4446(61)$ & \multicolumn{2}{|l|}{$1117(61)$} \\
\hline \multicolumn{4}{|l|}{ Race } \\
\hline White & $5989(83)$ & \multicolumn{2}{|l|}{$1481(81)$} \\
\hline Black & $671(9)$ & \multicolumn{2}{|l|}{$179(10)$} \\
\hline Other/unknown & $603(8)$ & \multicolumn{2}{|l|}{$170(9)$} \\
\hline \multicolumn{4}{|l|}{ Geography† } \\
\hline Urban county residence & $5524(76)$ & $1264(69)$ & (referent) \\
\hline Rural county residence & $1739(24)$ & $566(31)$ & 1.4 (1.3 to 1.6$)$ \\
\hline \multicolumn{4}{|l|}{ Means of self-harm } \\
\hline Cutting ${ }^{\dagger}$ & $1215(17)$ & 597 (33) & 2.6 (2.3 to 3.0$)$ \\
\hline Poisoning: drugs $†$ & $5168(71)$ & \multicolumn{2}{|l|}{$899(49)$} \\
\hline Poisoning: non-drugs $†$ & $600(8)$ & \multicolumn{2}{|l|}{$94(5)$} \\
\hline Other Meanst & 919 (13) & $441(24)$ & 2.7 (2.3 to 3.1$)$ \\
\hline \multicolumn{4}{|l|}{ Commodities } \\
\hline $\begin{array}{l}\text { Mental, behavioural and } \\
\text { neurological disorders } \\
\text { (F00-F09, F20-F99)† }\end{array}$ & $6295(87)$ & $1784(97)$ & 4.3 (3.1 to 5.8$)$ \\
\hline Suicidal ideation (R45.851) & $1215(17)$ & \multicolumn{2}{|l|}{316 (17) } \\
\hline $\begin{array}{l}\text { History of self-harm } \\
(\mathrm{Z} 91.5) \dagger\end{array}$ & $738(10)$ & $325(18)$ & 1.4 (1.2 to 1.6$)$ \\
\hline $\begin{array}{l}\text { Drug related disorder } \\
\text { (F11-F19) } \dagger\end{array}$ & $2726(38)$ & $809(44)$ & 1.5 (1.4 to 1.7$)$ \\
\hline $\begin{array}{l}\text { Alcohol related disorder } \\
\text { (F10) }\end{array}$ & $1627(22)$ & \multicolumn{2}{|l|}{$401(22)$} \\
\hline \multicolumn{4}{|l|}{ Chronic Disease Index† } \\
\hline Zero & $5608(77)$ & \multicolumn{2}{|l|}{$1466(80)$} \\
\hline One & $1373(19)$ & \multicolumn{2}{|l|}{$326(18)$} \\
\hline Two or more & $282(4)$ & $38(2)$ & \\
\hline No of visits $†$ & & & \\
\hline One & $6040(83)$ & $1638(90)$ & (referent) \\
\hline Two & $942(13)$ & $136(7)$ & 0.5 (0.4 to 0.6$)$ \\
\hline Three or more & $281(4)$ & $56(3)$ & 0.7 (0.5 to 1.0$)$ \\
\hline
\end{tabular}

Some rounding error for age and race group percentages in order to total $100 \%$. Comorbidities include list of relevant International Classification of Diseases, 10th Revision, Clinical Modification (ICD-10CM) codes in parentheses (all diagnoses fields reviewed). Chronic Disease Index based on Charlson Comorbidities Index.

*Compared to subset $(A+B)$.

†Cochran-Mantel-Haenszel general association $\mathrm{p} \leq 0.05$

$\ddagger$ Based on information from first discharge during 2017-2018 period.

\section{DISCUSSION}

\section{Interpretation/implications}

Results demonstrate that conservative case selection criteria may fail to identify populations with certain characteristics. In both models, certain subpopulations and patients with comorbidities, specifically mental health and drug-related disorders, were disproportionately under-represented when criteria were limited to injury principal diagnosis (subset A) or to those with initial encounters for self-harm (subset $(A+B)$ ). Mental healthrelated conditions are often associated with self-harm injury and suicide. ${ }^{8-102123}$ Additionally, means of self-harm was significantly different between subsets (both models); this can be predictive of repetition ${ }^{11}$ and suicide trajectory ${ }^{29}$ which can, in turn, guide prevention activities.

Use of the most conservative criteria (subset A), focused on a principal diagnosis of injury, does not adequately represent the scale of this important health issue. A comparison of ageadjusted rates by selection criteria (2017-2018) highlights the differences: patient-level rates increased by $65 \%$ going from subset $A$ to subset $(A+B)$ and by $26 \%$ from subset $(A+B)$ to the most comprehensive criteria (subsets $A+B+C$ ). Limiting surveillance to subset A may be detrimental to understanding the magnitude of the crisis and populations at risk, developing policy, and creating and funding programmes for prevention and care.

Based on our findings, we recommend employing methodology that is all inclusive (subsets $\mathrm{A}+\mathrm{B}+\mathrm{C}$ ) to conduct nonfatal self-harm hospitalisation surveillance for overall burden. Understanding the wide-reaching impact of this health concern is critical. Subsequent hospitalisations after the initial self-harm event still require a healthcare response and treatment. Understanding the magnitude of all self-harm encounters will impact response, including healthcare staffing, funding and programming. Subset $(\mathrm{A}+\mathrm{B})$ (restricted to initial encounters of self-harm) is most appropriate for incidence surveillance based on the evidence that subset A disproportionately excludes younger, rural patients and those with certain mental health-related comorbidities.

Patient-level data should be used to produce population statistics. The repetitive nature of this injury 610112023 makes it more relevant to create counts and rates based on individuals rather than visits. Crosby et al also noted this in their report on self-harm surveillance and establishing uniform definitions. ${ }^{14}$ Based on Wisconsin data for the most inclusive criteria (subsets $\mathrm{A}+\mathrm{B}+\mathrm{C}$ ), the patient-level age-adjusted rate for the study period was $18 \%$ lower than the visit-level rate. Use of patient-level data, however, will be determined by a jurisdiction's ability to link patient visits.

Though patient-level data provide information about the population impact, visit-level data may be appropriate based on one's analytical requirements. For instance, visit-level data would be useful for an assessment of healthcare burden.

\section{Limitations and future research}

One limitation of the study is that we rely on hospitalisation records to appropriately record instances of self-harm. We do not address sensitivity/specificity in regard to the use of selfharm ICD-10-CM codes which would require case confirmation studies involving medical record review. Record review would also assist with interpretation of the encounter data. A review of Wisconsin data revealed that, based on an all-inclusive dataset (subsets $\mathrm{A}+\mathrm{B}+\mathrm{C}$ ), $78 \%$ of all visits had a self-harm code indicating an initial encounter, $21 \%$ had a code indicating subsequent encounter (with no initial encounter code), and less than $1 \%$ were coded as self-harm sequelae encounter only. The same encounter distribution was found in the patient-level analysis. A better understanding of the significance of these codes and how they are employed may require a review of medical records and/ 
or clinical best practices. The difference between rates based on subset $(\mathrm{A}+\mathrm{B})$ and all combined (subsets $\mathrm{A}+\mathrm{B}+\mathrm{C}$ ) is significant. Therefore, a thorough review and analysis of subsequent encounters, specifically how these are distinct from initial encounters, and the practices of medical coders and interpretation of healthcare provider documentation, would be informative.

Another limitation of the study is that we have restricted analyses to Wisconsin residents admitted to Wisconsin hospitals. Wisconsin hospitals may apply ICD-10-CM coding and diagnosis prioritisation differently than other areas. Future research could repeat this work to determine if these findings are specific to Wisconsin or more generalisable.

\section{What is already known on the subject}

- Self-inflicted violence is a public health emergency though surveillance of nonfatal self-harm is not systematically conducted at the national, state or local level.

- An injury hospitalization case definition restricted to a subset based on principal diagnosis of injury may not be appropriate for this unique injury which is more likely to be repeated, have more return visits to healthcare, and result in suicide.

\section{What this study adds}

- This study analyzes several case selection criteria, each one more inclusive than the previous, and differences in population characteristics of those excluded or included by expansion or restriction of the criteria.

- Authors analyze population differences by case selection criteria at the patient-level and visit-level and discuss implications for surveillance.

Contributors All authors provided critical editorial input. BG contributed to the literature review. PI and OD contributed to the design and analysis of the study. PI drafted the manuscript.

Funding This publication was supported by the Grant Number, 5 NU17CE924837-04-00 funded by the Centers for Disease Control and Prevention.

Disclaimer The contents of this publication are solely the responsibility of the authors and do not necessarily represent the official views of the Centers for Disease Control and Prevention, the University of Wisconsin-Madison, the Wisconsin Department of Health Services, or Public Health Madison \& Dane County.

Competing interests None declared.

Patient and public involvement Patients and/or the public were not involved in the design, or conduct, or reporting, or dissemination plans of this research.

Patient consent for publication Not required.

Ethics approval This study is considered IRB exempt by the Common Rule Change under the umbrella of surveillance activities. Patient and public involvement in the study design, analysis and reporting was not considered appropriate. Analytic file provided by Office of Health Informatics, Division of Public Health, Wisconsin Department of Health Services.

Provenance and peer review Commissioned; externally peer reviewed.

Data availability statement Data may be obtained from a third party and are not publicly available.

Open access This is an open access article distributed in accordance with the Creative Commons Attribution Non Commercial (CC BY-NC 4.0) license, which permits others to distribute, remix, adapt, build upon this work non-commercially, and license their derivative works on different terms, provided the original work is properly cited, appropriate credit is given, any changes made indicated, and the use is non-commercial. See: http://creativecommons.org/licenses/by-nc/4.0/.

ORCID iD

Pamela Imm http://orcid.org/0000-0003-2850-1758

\section{REFERENCES}

1 Centers for Disease Control and Prevention, National Center for Injury Prevention and Control. Web-based Injury Statistics Query and Reporting System (WISQARS) [online], 2005. Available: www.cdc.gov/injury/wisqars [Accessed 29 Oct 2019].

2 Ting SA, Sullivan AF, Boudreaux ED, et al. Trends in US emergency department visits for attempted suicide and self-inflicted injury, 1993-2008. Gen Hosp Psychiatry 2012;34:557-65.

3 Mercado MC, Holland K, Leemis RW, et al. Trends in emergency department visits for nonfatal self-inflicted injuries among youth aged 10 to 24 years in the United States, 2001-2015. JAMA 2017:318:1931-3.

4 Klonsky ED, May AM, Glenn CR. The relationship between nonsuicidal self-injury and attempted suicide: converging evidence from four samples. J Abnorm Psychol 2013;122:231-7.

5 Hawton K, Zahl D, Weatherall R. Suicide following deliberate self-harm: longterm follow-up of patients who presented to a general hospital. Br J Psychiatry 2003:182:537-42.

6 Olfson M, Wall M, Wang S, et al. Suicide after deliberate self-harm in adolescents and young adults. Pediatrics 2018;141:e20173517.

7 Olfson M, Wall M, Wang S, et al. Suicide following deliberate self-harm. Am J Psychiatry 2017;174:765-74.

8 Duarte TA, Paulino S, Almeida C, et al. Self-harm as a predisposition for suicide attempts: a study of adolescents' deliberate self-harm, suicidal ideation, and suicide attempts. Psychiatry Res 2020;287:112553.

9 Cooper J, Kapur N, Webb R, et al. Suicide after deliberate self-harm: a 4-year cohort study. Am J Psychiatry 2005;162:297-303.

10 Sakinofsky I. Repetition of suicidal behavior. In: Hawton K, Van Heeringen K, eds. The International Handbook of suicide and attempted suicide. Chichester, West Sussex: John Wiley \& Sons Ltd, 2000: 385-404.

11 Lilley R, Owens D, Horrocks J, et al. Hospital care and repetition following selfharm: multicentre comparison of self-poisoning and self-injury. $B r J$ Psychiatry 2008; 192:440-5.

12 Whitlock J, Muehlenkamp J, Eckenrode J, et al. Nonsuicidal self-injury as a gateway to suicide in young adults. J Adolesc Health 2013;52:486-92.

13 Hedegaard H, Curtin SC, Warner M. Increase in suicide mortality in the United States, 1999-2018. NCHS data brief, no 362. National Center for Health Statistics, 2020. Available: https://www.cdc.gov/nchs/data/databriefs/db362-h.pdf [Accessed 11 May 2020].

14 Crosby AE, Ortega L, Melanson C. Self-directed violence surveillance: uniform definitions and recommended data elements, version 1.0. Centers for Disease Control and Prevention, National Center for Injury Prevention and Control, 2011. Available: www.cdc.gov/ violenceprevention/pdf/Self-Directed-Violence-a.pdf [Accessed 19 Sept 2019].

15 Centers for Disease Control and Prevention, National Center for Health Statistics. International Classification of Diseases, (ICD-10-CM/PCS) transition - background, 2015 Available: www.cdc.gov/nchs/icd/icd10cm_pcs_background.htm [Accessed 19 Sep 2019].

16 Cartwright DJ. ICD-9-CM to ICD-10-CM codes: what? why? how? Adv Wound Care 2013;2:588-92.

17 Hedegaard H, Johnson RL. An updated International Classification of Diseases, 10th Revision, Clinical Modification (ICD-10-CM) surveillance case definition for injury hospitalizations. National Health Statistics Reports; no 125. National Center for Health Statistics, 2019. Available: www.cdc.gov/nchs/data/nhsr/nhsr125-508.pdf [Accessed 19 Sept 2019].

18 Council of State and Territorial Epidemiologists. ICD-10-CM injury surveillance toolkit, 2019. Available: resources. cste.org/Injury-Surveillance-Methods-Toolkit [Accessed 29 Oct 2019]

19 Hedegaard H, Schoenbaum M, Claassen C, et al. Issues in developing a surveillance case definition for nonfatal suicide attempt and intentional self-harm using International Classification of Diseases, Tenth Revision, Clinical Modification (ICD-10-CM) coded data. National Health Statistics Reports; no 108. National Center for Health Statistics, 2018. Available: www.cdc.gov/nchs/data/nhsr/nhsr108.pdf [Accessed 19 Sept 2019].

20 Goldman-Mellor S, Kwan K, Boyajian J, et al. Predictors of self-harm emergency department visits in adolescents: a statewide longitudinal study. Gen Hosp Psychiatry 2019;56:28-35.

21 Weber NS, Fisher JA, Cowan DN, et al. Descriptive epidemiology and underlying psychiatric disorders among hospitalizations with self-directed violence. PLoS One 2013;8:e59818.

22 Peterson C, Xu L, Leemis RW, et al. Non-Fatal self-inflicted versus undetermined intent injuries: patient characteristics and incidence of subsequent self-inflicted injuries. Inj Prev 2019;25:521-8.

23 Lundin A, Lundberg I, Allebeck P, et al. Psychiatric diagnosis in late adolescence and long-term risk of suicide and suicide attempt. Acta Psychiatr Scand 2011;124:454-61.

24 Colman I, Dryden DM, Thompson AH, et al. Utilization of the emergency department after self-inflicted injury. Acad Emerg Med 2004;11:136-42.

25 Wisconsin State Legislature. Wisconsin Statutes, chapter 153. Available: docs.legis. wisconsin.gov/statutes/statutes/153 [Accessed 10 Sept 2019]. 
26 Wisconsin Office of Rural Health. Defining rural for Wisconsin, 2016. Available: worh. org/WisRuralAreas [Accessed 10 Sept 2019].

27 National Center for Health Statistics. International Classification of Diseases, Tenth Revision, Clinical Modification (ICD-10-CM), 2020. Available: www.cdc.gov/nchs/icd/ icd10 cm.htm [Accessed 10 March 2020].
28 Quan $\mathrm{H}$, Sundararajan $\mathrm{V}$, Halfon $\mathrm{P}$, et al. Coding algorithms for defining comorbidities in ICD-9-CM and ICD-10 administrative data. Med Care 2005;43:1130-9.

29 Bergen $\mathrm{H}$, Hawton $\mathrm{K}$, Waters $\mathrm{K}$, et al. How do methods of non-fatal self-harm relate to eventual suicide? J Affect Disord 2012;136:526-33. 